OSCAR TACCA

\title{
HUMOR EN EL EXTRANJERO DE CAMUS
}

En el variado complejo conceptual, afectivo y sensorial, esencialmente ambiguo, que la lectura de El extranjero suscita, hay una veta que, aunque no de superficie, fluye con su presencia constante y efecto perdurable en el ánimo del lector: el humor.

Más que de una veta que se soterra y reaparece convendría, tal vez, hablar de un hálito sutil pero indudable que recorre toda la novela. Pero el humor de $E l$ extranjero es $\tan$ tenue que el lector no familiarizado, a la, primera lectura ( $y$, naturalmente, habiéndose iniciado con la noticia de la muerte de la madre del protagonista) avanza desconeertado, duda, vacila en reconocerlo o admitirlo.

De efecto catártico, este ingrediente no ha sido ajeno al éxito del libro. Se trata, en realidad, de tres vertientes de un mismo flujo, difíciles de separar por su mutua implicación: la comicidad, el humor y la ironía, de distinción netamente subjetiva a menos que, objetiva y abusivamente, digamos que la comicidad se traduce en la risa, el humor en la sonrisa, la ironía en un goce más escondido y sutil que ni siquiera llega a los labios.

Esa veta, con excepción de unos pocos tratamientos que por su agudeza y pertinencia, mencionaremos, no ha merecido la atención de la crítica. No es extraño, por lo demás, que así ocurriera. La materia del relato no aparecía, a los primeros comentadores, como particularmente apta para el análisis del humor: cuestiones de más grave trascendencia y profundidad reclamaron la atención. En tal nivel, "el humor, el drama y el lirismo se mezclan sutilmente para crear un tono, único en la literatura contemporánea". (1) 
Hay, empero, una recurrente comicidad, humor e ironía en El extranjero. Camus no ignoró este aspecto de su obra. En un artículo aparecido en Combat, en 1944, escribe: "No nos es extraña la ironía". (2) En 1959, Jean-Claude Brisville le formula, entre otras, la siguiente pregunta: " ${ }_{i} \mathrm{Hay}$ en su obra un tema, a su juicio importante, que usted estime descuidado por sus comentadores?", a la que Camus responde: "El humor". (3)

De dónde procede, pues, el innegable humor que alienta en El extranjero. Digamos, por de pronto, que a nuestro juicio está presente en todo el libro, y no sólo (como algunos han sostenido) en la segunda parte. Innecesario sería abundar aquí en detalles sobre la conocida diferencia entre ambas partes (en relación con su tema, tiempo, momento de narración). En la primera le han sucedido a Meursault muchas cosas: ha muerto su madre, ha trabado relación con Raymond, con María, ha matado al árabe. En la segunda, en cambio, no pasa nada: se trata del proceso originado por lo acontecido en la primera (para nosostros, en realidad, el 'procesamiento' de la primera). En aquélla, Meursault es un individuo sin importancia, juguete del destino; en ésta, a pesar de que le cuesta comprender, a pesar de su buena voluntad y a pesar de que todo el aparato de la justicia pareciera prescindir de él (concedámoselo: "Es importante ser el acusado"... !) va a asumir, por la fuerza de los hechos, gradualmente, conciencia de sujeto de un destino aciago, ineluctable, absurdo.

En la primera parte la comicidad predominante radica en las situaciones, la descripción, o el simple registro de cosas, ambientes y personas; en la segunda, primordialmente en el relato, observaciones y acotaciones de Meursault (referidas a las circunstancias de la instrucción y el proceso). En la primera predomina, pues, el humor, en la segunda la ironía. Dos citas de Mitterand nos ayudarían a precisar el sentido de uno y otra: "El humor consiste en echar sobre el mundo una mirada falsamente ingenua, para hacer surgir lo ridículo y lo absurdo"; "es por lo que su lenguaje [ el de Meursault ] , sin que él tenga conciencia, es una fuente permanente de ironía." (4)

La cuestión, no obstante, suscita ineludiblemente otra, de carácter más general (5) pero no menos perentoria, y que los críticos han rozado o abordado con diferente respuesta: a quién debe atribuirse el humor $i^{a}$ Meursault o a Camus? (6). Conviene, pues, ver y exponer el asunto con claridad. (La solución contribuirá, de paso. a disipar la duda o controver- 
sia sobre la pretendida incoherencia o contradicción del personaje y subrayará la diferencia de humor - ya aludida- entre la primera y la segunda parte).

Meursault ha vivido, hasta el momento de matar al árabe, en pleno acuerdo con la naturaleza, con el prójimo y consigo mismo. Su comportamiento es natural e irreflexivo, su visión del mundo simple y desprejuiciada, su registro neutro e indiferente. Meursault no es un humorista. Es ese comportamiento ("si ella lo deseaba podíamos casarnos"), esa visión ("nunca había notado hasta qué punto podían tener vientre las ancianas"), ese registro ("después del entierro será un asunto archivado") lo que, a nuestra conducta 'socializada', a nuestra visión preconcebida, a nuestro lenguaje más connotativo que denotativo resulta curioso, sorprendente, colindante con el humor. La conducta, la mirada y la palabra de Meursault no son arbitrarias. $\mathrm{Y}$ aquí sí corresponde atribuir al arte de Camus el sabio empleo de un lenguaje hábil y eficaz en que el narrador desborda al locutor, sugiriendo mucho más de lo que dice el personaje. En otras palabras, el autor ha sabido extraer del limitado registro de Meursaul -no de su propio registro- el mayor rendimiento posible, el más alto coeficiente narrativo. Pero esto es lo genuino del arte de la novela, y especialmente de la novela contemporánea.

En la segunda parte, y en razón de la experiencia vivida (la muerte del árabe) y del nuevo contex to en que se desenvuelve su vida, el protagonista relata las alternativas del juicio, se torna más lúcido, apunta miopías, incongruencias y extravagancias de la justicia. Meursault no es tampoco un ironista. Pero como su comentario pone de relieve el absurdo de la sociedad en general y de la justicia en particular, se ha subrayado la comicidad de esta segunda parte. Aquí, más que en los seres, las cosas y las circunstancias, el humor radica en la palabra de Meursault. Aunque ambos tipos de humor coexisten, su dosificación parece reclamar una últil distinción: en la primera predomina la comicidad de situación, en la segunda la de lenguaje.

Procuremos contemplarlas más de cerca. Los efectos de humor del primer tipo (abundantes en la primera parte) provienen fundamentalmente: 
a) de una torpeza de conducta:

Me pareció que el cortejo fúnebre marchaba un poco más de prisa. [ . . . ] Pérez me pareció muy lejos, perdido en una nube de calor; luego, no lo divisé más. Lo busqué con la mirada y vi que había dejado el camino y tomado a campo traviesa. Comprobé también que el camino doblaba delante de mi. Comprendí que Pérez, que conocía la región, cortaba campo para alcanzarnos. Al dar la vuelta se nos había reunido. Luego lo perdimos. Volvió a tomar a campo traviesa, y asi varias veces.

(p. 29; I, 1134) ${ }^{(7)}$

o de palabra:

Pedí dos días de licencia a mi patrón [ para velar a mi madre ]. Pero [ él ] no parecía satiafecho. Llegué a decirte: "No es culpa mía."

(p. 11; I, 1125)

b) de una mirada desprejuiciada e ingenua, de un mero registro de la realidad, que nos vale algunas descripciones o retratos que rayan en lo grotesco:

[ Raymond ] también tiene una sola pieza, con una cocina sin ventana. Sobre la cama hay un ángel de estuco blanco y rosa, fotos de campeones y dos o tres clisés de mujeres desnudas.

(p. 46; 1, 1143)

Pasó primero una familia que iba de paseo: dos niños de traje marinero, los pantalones sobre las rodillas, un tanto trabados dentro de las ropas rígidas, y una niña con un gran lazo color de rosa y zapatos de charol. Detrás de ellos, una madre enorme vestida de seda castaña, y el padre, un hombrecillo bastante endeble que conocía de vista. Llevaba sombrero de paja, corbata de lazo, y un bastón en la mano. Al verle con su mujer comprendí por qué en el barrio se decía de él que era distinguido.

(p. 36:1. 1138) 
c) de ciertas comparaciones inocentes:

Delante de la puerta estaba el coche fúnebre. Lustroso, oblongo y brillante, hacia pensar en una caja de lápices.

(p. 26; I, 1133)

d) de un singular desapego, indiferencia o flema: la amistad, el amor o la ambición hallan en Meursault idéntica respuesta, sea al patrón que le propone trasladarlo a París, invitándolo "a una vida que debía de gustarle":

Dije que sí, pero que en el fondo me daba lo mismo.

(p. 64; I, 1153)

a Raymond, que decide hacerlo su amigo:

Me daba lo mismo ser su camarada ...

(p. 51; I, 1146)

o que lo solicita como testigo:

A mí me daba lo mismo, pero no sabía qué debía decir.

(p. 58; 1, 1150)

o a María, que le pregunta si quiere casarse con ella:

Dije que me daba lo mismo y que podríamos hacerlo si lo quería.

(p. 65; I, 1154)

e) de una simplificación o recorte de la realidad: 
[ María ] me preguntó cómo era [ París ] . Le dije: "Es sucio. Hay palomas y patios oscuros. La gente tiene la piel blanca."

(p. 66; I, 1154)

Cuánto más, si esa realidad es psicológica:

El presidente contestó que [ . . ] le complacería que precisara los motivos que habían inspirado mi acto [ asesinato del árabe ]. Mezclando un poco las palabras y dándome cuenta del ridículo, dije rápidamente que había sido a causa del sol.

(p. 148; 1, 1196)

\section{f) de fragmentos narrativos que son en si breves "escenas":}

[ El agente ] golpeó con más fuerza y, al cabo de un momento, la mujer lloró otra vez y Raymond abrió. Tenía un cigarrillo en la boca y el aire dulzón. La muchacha se precipitó hacia la puerta y declaró al agente que Raymond le había pegado. "Tu nombre", dijo el agente. Raymond respondió. "Quítate el cigarrillo de la boca cuando me hablas", dijo el agente. Raymond titubeó, me miró y se quedó con el cigarrillo. Entonces el agente le cruzó la cara al vuelo con una bofetada espesa y pesada, en plena mejilla. El cigarrillo cayó algunos metros más lejos. Raymond se demudó, pero no dijo nada en seguida. Luego preguntó con voz humilde si podía recoger la colilla. El agente respondió que sí y agregó: "Pero la próxima vez sabrás que un agente no es un monigote." Mientras tanto, la muchacha lloraba y repetía: “ ¿Me golpeó! ¡Es un rufián!" "Señor agente", preguntó entonces Raymond, “ ¿permite la ley que se llame rufián a un hombre?" Pero el agente le ordenó "cerrar el pico". Raymond se volvió entonces hacia la muchacha y le dijo: "Espera, chiquita, ya nos volveremos a encontrar."

(p. 56; I, 1149)

Le pregunté [ a Salamano ] dónde estaba el perro. Bruscamente me respondió que se había marchado. Luego, de golpe, habló con volubilidad: "Lo llevé al Campo de Maniobras como de costumbre. Había mucha gente en torno de los kioscos de saltimbanquis. Me detuve a mirar "El Rey de la Evasión'. Y cuando quise seguir no estaba más alli." 
g) de las contradicciones humanas:

Tras otro momento de silencio [ María ] murmuró que yo era extraño, que sin duda me amaba por eso mismo, pero que quizás un día le repugnaría por las mismas razones.

(p. 66; I, 1154)

Le fastidiaba "sentir todavía deseos de hacer el coito con ella". Pero quería castigarla.

(p. 49; I, 1145)

Yo escuchaba y oía que se me juzgaba inteligente. Pero no comprendía bien cómo las cualidades de un hombre común podían convertirse en cargos aplastantes contra un culpable.

(p. 144; I, 1194)

h) de una desmitificación de las creencias:

Me preguntó si había sentido pena aquel día. [ $[\ldots]$ El día del entierro de mamá estaba muy cansado y tenía sueño, de manera que no me di cuenta de lo que pasaba. Lo que podía afirmar con seguridad es que hubiera preferido que mamá no hubiese muerto.

(p. 95; I, 1170)

o de las instituciones:

v. gr. de la justicia:

El hombre de toga roja se sentó en el sillón del centro; colocó el birrete delante de sí, se enjugó el pequeño cráneo calvo con un pañuelo y declaró que la audiencia estaba abierta.

(p. 123; I, 1184)

v. gr. del periodismo:

[ El gendarme ] me dijo: "Ahí estár." Pregunté: “ ¿Quiénes?" y repitió: "Los periódicos." Conocía a uno de los periodistas que $[\ldots]$ se di- 
rigió a mi, sonriente. Me dijo que esperaba que todo saldría bien para mí. Le agradeci, y agregó: "Usted sabe, hemos hinchado un poco el asunto. El verano es la estación vacía para los periódicos. Y lo único que valía algo era su historia y la del parricida." Me mostró en seguida, en el grupo que acababa de dejar, a un hombrecillo que parecía una comadreja cebada, con enormes gafas de aro negro. Me dijo que era el enviado especial de un diario de Parí: "No ha venido por usted, desde luego. Pero como está encargado de informar acerca del proceso del parricida, se le ha pedido que telegrafie sobre su aunto al mismo tiempo." Ahi, otra vez, estuve a punto de agradecerle. Pero pensé que seria ridículo.

(p. 121; I, 1183)

i) del desajuste entre el ideal y la realidad:

En su juventud [ Salamano ] tuvo intención de dedicarse al teatro: en el regimiento representaba en las zarzuelas militares. Pero había entrado finalmente en los ferrocarriles y no lo lamentaba porque ahora tenía un pequeño retiro.

(p. 69; I, 1156)

En la segunda parte, como ya hemos anticipado, el humor proviene esencialmente del lenguaje. Pero no tanto del lenguaje en sí-y de sus inveterados recursos, algunos de los cuales destacaremos ${ }^{(8)}$ - sino principal: mente del inusitado empleo del discurso narrativo.

El lenguaje del El extranjero ha sido acertadamente calificado por numerosos críticos de neutro y gris, monótono y "nasillard", chato y uniforme, pero desde nuestro presente interés preferimos subrayar algunos efectos más específicos, especialmente derivados de su carácter:

a) seco y terminante:

El otro me dijo: "Baja del tranvía si eres hombre." Yo le dije: "Vamos, quédate tranquilo." Me dijo que yo no era hombre. Entonces bajé y le dije: "Basta, es mejor; o te rompo la jeta." Me contestó: “ ¿Con qué?" Entonces le pegué. Se cayó. Yo iba a levantarlo. Pero me tiró unos puntapiés desde el suelo. Entonces le di un rodillazo y dos taconazos. Tenía la cara llena de sangre. Le pregunté si tenía bastante. Me dijo: "Si."

(p. 46; I, 1143) 
b) contrastante:

Esa tarde reflexioné y me dije que [María ] quizás se habría cansado de ser la amante de un condenado a muerte.

(p. 165; I, 1204)

c) paródicamente hiperbólico:

[ El procurador ] decía que, en realidad, yo no tenía alma en absoluto y que no me era accesible ni lo humano, ni uno solo de los principios morales que custodian el corazón de los hombres.

(p. 145; I, 1195)

d) o a la inversa, reductor, 'desinflante':

Necesité tiempo para comprenderle en ese momento porque decía "su amante" y para mí ella era María.

(p. 142; I, 1194)

El presidente me dijo en forma extraña que, en nombre del pueblo francés, se me cortaría la cabeza en una plaza pública.

(p. 153; 1, 1199)

e) insidiosamente convencional:

"En fin, zse le acusa de haber enterrado a su madre o de haber matado a un hombre?" El público rió. El procurador se reincorporó una vez más, se envolvió en la toga y declaró que era necesario tener la ingenuidad del honorable defensor para no advertir que entre estos dos órdenes de hechos existía una relación profunda, patética, esencial.

(p. 139; I, 1191) 
Hemos dicho, no obstante, que la ironía, especialmente notoria en la segunda parte, provenía no tanto de aquellos inveterados recursos del lenguaje (hipérbole, parodia, contraste . . . ) sino preferentemente del entrecruzamiento, o más bien, del ingenioso trastrueque de las distintas modalidades del discurso. Es decir, no tanto del estilo sino (valga el retruécano) de los estilos: directo, indirecto, indirecto libre.

El discurso directo ha sido utilizado por Camus con parsimonia en $E l$ extranjero. De él ha obtenido los efectos que la narración frecuentemente procura cuando a él recurre: concisión, fidelidad, imagen aparentemente objetiva de la realidad (amén de una ruptura de la monotonía por la alternancia de voces). $\mathrm{Y}$ de tales efectos, una dosis adicional de humor:

Le dije: “¿Cómd?" Repitió señalando al cielo: "Castiga." Dije: "Si." Poco después me preguntó: "¿Es su madre la que va ahí?" Otra vez dije: "Sí." “Era vieja?" Respondí: "Más o menos."

(p. 29; I, 1134)

De cualquier modo, no cae el relato en un abuso del habla vulgar o en el socorrido recurso del folklorismo, del cagayou. (9) El discurso indirecto (propio del lenguaje narrativo), que predomina, da lugar a frecuentes efectos de ironía. El recurso más rico consiste en la reproducción, en estilo indirecto, de la expresión oral, habitualmente recogida por el estilo directo:

Los tranvías siguientes trajeron a los jugadores, que reconocí por las pequeñas valijas. Gritaban y cantaban a voz en cuello que su club no moriría jamás.

(p. 38; I, 1139)

Pero es el empleo del discurso indirecto libre la fuente más abundante de ironía. Fitch ha mostrado, en un valioso estudio ${ }^{(10)}$, cómo este tipo de discurso (cuyo carácter "mimético y potencialmente irónico" destacara Stephen Ullmann (11) ) permite, al trasladar el lenguaje privándolo de su espontaneidad y circunstancia, subrayar el vacío de la retórica tribunalicia: 
"Este mismo tribunal, señores, va a juzgar mañana el más abominable de los crímenes: la muerte de un padre." Según él, la imaginación retrocedía ante este atroz atentado. Osaba esperar que la justicia de los hombres castigaría sin debilidad. Pero, no temia decirlo, el horror que le inspiraba este crimen cedía casi frente al que sentía delante de mi insensibilidad.

(p. 146; I, 1195)

o la superfluidad de las fórmulas jurídicas:

Decía que se había acercado a [ mi alma ] y que no había encontrado nada, señores jurados.

(p. 145; I, 1195)

Pero el efecto mayor (aunque de origen más recóndito) provięne, según sagazmente lo muestra, de la alternancia de los discursos -directo, indirecto, indirecto libre- uno recuperado por otro:

Me dijo que era imposible, que todos los hombres creían en Dios, aun aquéllos que le volvian la espalda. Tal era su convicción, y si alguna vez llegara a dudar, la vida no tendría sentido. “¿Quiere usted”, exclamó, "que mi vida no tenga sentido?"

(p. 101; I, 1173)

Para concluir, preguntó a Raymond cuáles eran sus medios de vida, y como el último respondiera: "guardalmacén", el abogado general declaró a los jurados que el testigo ejercía notoriamente el oficio de proxeneta. Yo era su cómplice y su amigo. Se trataba de un drama crapuloso de la más baja especie, agravado por el hecho de tener delante a un monstruo moral.

(p. 138; I, 1191)

La ambigüedad esencial del indirecto libre permite desnaturalizar, minimizar, ridiculizar tanto a los jueces (ante Meursault) como a Meursault 
(ante los jueces). Cargado de incuestionable ironía, se trata de un sutil (y travieso) juego de sustituciones: de una parte, el abogado defensor fabrica, sustituye con un yo artificial (pour les besoins de la cause ...) el yo auténtico del personaje:

.. escuché que decía: "Es cierto que yo maté." Luego continuó en el mismo tono, diciendo "yo" cada vez que hablaba de mí. Yo estaba muy asombrado.

(p. 148; I, 1196)

De otra parte, Meursault sustituye su propio yo con el yo fabricado por el procurador:

Lo que decía era plausible. De acuerdo con Raymond yo había escrito la carta que debía atraer a la amante y entregarla a los malos tratos de un hombre de "dudosa moralidad". Yo había provocado en la playa a los adversarios de Raymond. Este había resultado herido. Yo le había pedido el revólver. Había vuelto solo para utilizarlo. Había abatido al árabe, tal como lo tenía proyectado. Había tirado una vez. Había esperado.

(p. 143; I, 1194)

Hay, sin duda, un hálito de humor que recorre El extranjero. ¿Es Meursault el responsable? Una aproximación, por su similar naturaleza, se impone. Se ha hablado de los "pasajes líricos", de la "poesía" de El extranjero. Pero Meursault no es un poeta. La poesía de Meursault es la que resulta de una mirada limpia y desprejuiciada del mundo, desinhibida de toda convención. Con alguna irrelevante excepción, la poesía de Meursault proviene de una mera intensificación de los rasgos permanentes de su temperamento -claridad, inmediatez, sensualidad-o de su habla -economía, rigor, exactitud-. Podría decirse de su palabra lo que Camus dice de la novela clásica francesa: "la llama más viva corre en un lenguaje exacto". (12) Meursault - lo hemos dicho- no es tampoco un humorista. Somos nosotros quienes declaramos poético o humorístico su lenguaje inocente. a raiz de los recursos diestramente instilados por el autor. En todo caso. Veursault es un pocta! un humorista inconsciente. O si se prefiere, 
semiconsciente: "semiconciencia análoga a las del vatevidente-profeta o del niño que desborda fantasías ingenuas en el juego" como dice Castagnino refiriéndose a la elaboración de los artificios formales que modelan el poema (13).

Ese humor, por la materia misma del libro, es escondido y sutil. Deja al lector en suspenso. Se trata de un humor de efecto retardado. Aun así, es (cualitativamente) de distinto orden en la primera y en la segunda parte. En aquélla es preferentemente de origen semántico, en ésta de origen retórico: más bien humor en la vida de Meursault (primera parte), más bien ironía en su racconto (segunda). Si todo lenguaje es un código -nos dice Dominique Noguez- el humor es un sobrecódigo. Esto nos parece más cierto aún de la ironía que del humor. En la primera parte podría decirse que es la situación, o el ambiente, o los personajes; es decir, la sustancia misma la que, en una suerte de reacción química normal, se transforma en comicidad. En la segunda (más sutilmente pero de modo peculiar por su carácter inasible) es un empleo muy especial del discurso, el indirecto libre, lo que sin quitar ni sumar nada a la situación, al ambiente o a los personajes, los transforma, añade un plus de comicidad, la ironía, en el relato. El recurso - el empleo del indirectolibre-interviene pues, verdaderamente, como un catalizador, que actúa simplemente por presencia. Si, como tantas veces se lo ha dicho o insinuado, el arte de Camus es oblicuo, neda más cierto que el carácter oblicuo de su humor. 
1. Henri Mitterand, "le langage de Meursault", in Le français dans le monde, N. 62, Paris, 1969, p. 7.

2. "Autocritique" (Combat, 22.11.44) in Actuelles, Gallimard, Paris, 1950, p. 41.

3. "Réponses à Jean-Claude Brisville", in A. Camus, Essais, Gallimard, Bibl. de la Pléiade, Paris, 1965, p. 1922.

4. H. Mitterand, op. cit., págs. 10 y 8 , respectivamente.

5. Que en otro lugar hemos sintetizado asi: "Y es que la diferencia fundamental entre toda la critica elaborada sobre $E l$ extranjero reside quizás en que una parte de ella busca su explicación, literariamente, por la vía del autor-olvidándose de Meursault- mientras la otra (no por ello menos literaria, pero con un concepto distinto de lo literario) ve a Meursault como responsable.del texto." Cf. O. Tacca, " $L$ 'Etranger comme récit d'auteur-transcripteur" in Albert Camus 1980, University Presses of Florida, Gainesville, 1980.

6. Pierre-Louis Rey la registra netamente: "Un punto de discusión entre los comentadores de El extranjero es saber si Meursault es un humorista, o si no es más que un agente involuntario del humor de Camus." L'Etranger. Camus. Analyse critique, Hatier, Paris, 1970, p. 55).

7. El número de página corresponde a la edición: A. Camus, El extranjero, Emecé, B8. As., 1949. La referencia consignada en segundo término remite a la edición en francés: A. Camus, Théâtre, récits, nouvelles, Gallimard, Bibl. de la Pléiade, Paris, 1963. Hemos alterado levemente la traducción, haciéndola más fiel al original, cuando lo hemos creído necesario.

8. Como este artículo presenta sus ejemplos en la versión española, procuramos escoger aquellos que conservan el efecto. El lector debe tener en cuenta lo que siempre 'se pierde' en la traducción, amén de otros recursos que son por naturaleza intransferibles.

9. Lenguaje popular de Argel. 
10. B. T. Fitch, “Aspects de l'emploi du discours indirect libre dans $L$ 'Etranger”, in Albert Camus 1, La Revue des Letres Modernes, Paris, 1968.

11. Stephen Ullmann, "Reported speech and internal monologue in Flaubert" in Syle in the French Novel, Oxford, Basil Blackwell, 2eme. éd., 1964.

12. “L intelligence et l'échafaud", in A. Camus, Théâtre, récits, nouvelles, Gallimard, Bibl. de la Pléiade, Paris, 1962, p. 1888.

13. Raúl H. Castagnino, Fenomenología de lo poético, Plus Ultra, Bs. As., 1980, p. 82 . 